\title{
EFFECTIVENESS OF ULTRASOUND-GUIDED MODIFIED PECTORAL NERVE BLOCK (PECS II) FOR POST-OPERATIVE PAIN RELIEF AFTER MODIFIED RADICAL MASTECTOMY (MRM)
}

\author{
Azmat Riaz, Mudasir Saleem, Khalid Mahmood*, Kaukab Majeed, Zaki Hussain**, Asad Ullah***
}

Pak Emirates Military Hospital/National University of Medical Sciences (NUMS) Rawalpindi Pakistan, ${ }^{*}$ Combined Military Hospital Quetta/National University of Medical Sciences (NUMS) Pakistan, ${ }^{* *}$ Combined Military Hospital Kohat/National University of Medical Sciences (NUMS) Pakistan, ${ }^{* * *}$ Combined Military Hospital Multan/National University of Medical Sciences (NUMS) Pakistan

\begin{abstract}
Objective: To find the effectiveness of ultrasound guided modified pectoral nerve block (PECS II) versus conventional analgesics for post-operative pain relief in women undergoing modified radical mastectomy.

Study Design: Quasi experimental study.

Place and Duration of Study: Department of Anaesthesia, Pak Emirates Military Hospital Rawalpindi Pakistan, from May 2018 to Oct 2019.

Methodology: A total of 74 adult female patients scheduled for elective unilateral modified radical mastectomy under general anaesthesia were randomized into two groups, pectoral nerve block II (P) group ( $n=37)$ and control (C) group (n=37). An ultrasound-guided pectoral nerve block II block was performed using $30 \mathrm{ml}$ of $0.25 \%$ Bupivacaine in pectoral nerve block II group after induction of general anaesthesia. In control group (C), patients received only general anaesthesia. Primary outcome measure was opioid consumption in first 24 hours, and the secondary outcome was pain at the breast and axillary region measured using the numerical rating scale (NRS) in first 24 hours at fixed intervals after surgery. Patient satisfaction was evaluated upon discharge using a 4-point scale.

Results: Nalbuphine consumption was significantly reduced in pectoral nerve block group as compared to control group. Patients in pectoral nerve block II group experienced much less pain because their numerical rating scale was lower than the control group in postoperative period. Patient satisfaction was found to be high in pectoral nerve block II group.

Conclusion: The pectoral nerve block II block is a simple block which provides excellent analgesia for modified radical mastectomy. It can be used for balanced anaesthesia, decrease intra-operative anaesthetic requirements and provide post-operative analgesia.
\end{abstract}

Keywords: Breast surgery, Modified radical mastectomy, Pectoral nerve block, Regional anaesthesia.

This is an Open Access article distributed under the terms of the Creative Commons Attribution License (https://creativecommons.org/licenses/by-nc/4.0/), which permits unrestricted use, distribution, and reproduction in any medium, provided the original work is properly cited.

\section{INTRODUCTION}

Mastectomy can lead to significant postoperative pain ${ }^{1}$. Modified radical mastectomy (MRM) is a painful procedure and patients usually demand heavy doses of analgesics to overcome this pain. In first 24 hours, they can require up to $48 \mathrm{mg}$ of morphine which puts them at risk of developing opioid related side-effects ${ }^{2}$. Management of acute post-operative pain in these patients is also important because it can also lead to persistent pain after breast cancer surgery ${ }^{3,4}$. Thoracic epidural block has been found effective for management of breast surgery pain but it carries risk of untoward effects like nerve damage, intravascular injection leading to toxicity, total spinal anaesthesia and formation of epidural hematoma ${ }^{5,6}$. Para-vertebral block is an alternate technique for providing post-operative pain but most anaesthetists are not familiar with this technique. It is also not without risk of complications ${ }^{7}$. A recently introduced PECS II block is a simple and easy-to-learn

Correspondence: Dr Azmat Riaz, Classified Anaesthetist, Pak Emirates Military Hospital, Rawalpindi Pakistan

Received: 08 Apr 2020; revised received: 09 Sep 2020; accepted: 17 Sep 2020 technique. Moreover, it is found to be a safe and effective pain-relieving technique in patients undergoing MRM $^{8,9}$. In pectoral block injection of local anaesthetic is made between the two pectoralis muscles blocking medial and lateral pectoral nerves. In PECS II block local anaesthetic is additionally injected between serratus anterior and pectoralis minor muscles to block intercostal and intercosto-brachial nerves. Our study is aimed to compare postoperative usage of opioid and patient satisfaction score in PECS II block group with that of control group in the first 24 hours after MRM.

\section{METHODOLOGY}

This study was conducted at department of Anaesthesia, Pak Emirates Military Hospital Rawalpindi, from May 2018 to October 2019. Study was approved by hospital ethics committee (ref no. A/28/EC/87) and we took written informed consent from patients. A total of 74 women who were scheduled forunilateral modified radical mastectomy (MRM) were selected as study subjects. Inclusion criteria was patients with ASA I and II physical status and age between 20-70 years. Exclusion criteria was patients having history of 
allergy to local anaesthetics, pregnancy, anticoagulant use, BMI $\geq 35 / \mathrm{kg} / \mathrm{m}^{2}$ or significant neurological or psychiatric disorder. Using a computer-generated randomization, we divided patients into two groups of 37 patients each. During preoperative visit, demographic data was recorded and procedure was explained to patients. Numerical rating score was also explained to patients and written informed consent was taken. In the operating room after insertion of intravenous cannula all patients received midazolam $2 \mathrm{mg}$ and nalbuphine $10 \mathrm{mg}$. We monitored all patients with pulse oximetry, ECG, blood pressure and capnography. Propofol $2 \mathrm{mg} / \mathrm{kg}$ was used as induction agent and then atracurium $0.5 \mathrm{mg} / \mathrm{kg}$ was injected for intubation of trachea. Anaesthesia was maintained with isoflurane $1.5-2 \%$ in $50 \%$ oxygen.

PECS II block was performed in PECS II group under ultra-sound guidance by a consultant anaesthetist having experience of $>50$ blocks. Patients were placed supine and upper limb was abducted. Skin was sterilised by using hexiprep ${ }^{\circledR}$ (Ethy. High frequency linear probe (6-12 MHz, Sonosite, USA) was first placed in infra-clavicular region and then moved laterally till pectoralis major and minor muscles were identified. Probe was then moved more laterally and 3rd and 4th ribs and serratus anterior muscle along with both pectoralis muscles were identified as shown in fig- 1 . In-plane technique was used to insert a 50-mm nerveblock needle (B Braun, Germany), as shown in fig-2 and $15 \mathrm{ml}$ of bupivacaine $0.25 \%$ was injected between serratus anterior and pectoralis minor muscle after negative aspiration. An additional $10 \mathrm{ml}$ of Bupivacaine $0.25 \%$ was injected between both pectoralis muscles after a little withdrawal of needle.

Post-operatively patients were kept in post anaesthesia care unit (PACU). Postoperative analgesia was provided with on-demand nalbuphine. We used NRS for pain measurement $(0=$ no pain and $10=$ worst pain $)$. Intravenous ondansetron $8 \mathrm{mg}$ was used for treatment of nausea or vomiting. Following 4-point satisfaction score was used to record satisfaction of patients $(0=$ poor, $1=$ fair, $2=$ good, $3=$ excellent). Anaesthesia residents in PACU and trained nurses in post-operative ward who were blinded to patient groups kept the record of data. X-ray chest was performed for any patient having difficulty in breathing or desaturating. Primary outcome of our study was consumption of nalbuphine in the first 24 hours. Pain intensity and patient satisfaction scores were secondary outcomes of study. Any complication of the PECS II block (pneumothorax, hematoma formation and local anaesthetic toxicity) and untoward effects of analgesics e.g. nausea, vomiting, dizziness or respiratory depression were also recorded. Quantitative variables like age, weight, BMI were presented in the form of mean \pm SD and range. SPSS-20 (Chicago, Illinois) was used for statistical analysis. Independent sample t-test was used for statistical analysis of nominal data. The $p<0.05$ was considered significant.
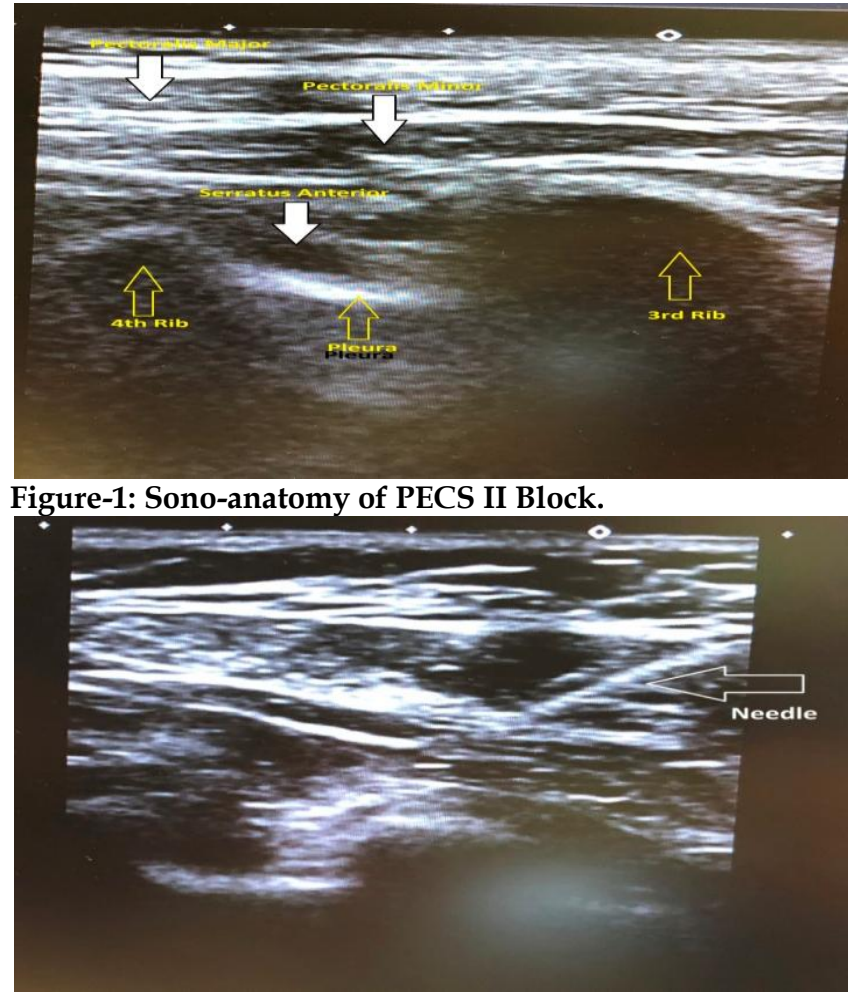

Figure-2: Needle visualization during block.

\section{RESULTS}

We included 74 patients undergoing MRM in this study. As shown in table-I both study groups were comparable in age, weight, BMI and duration of surgery.

Patients in PECS II group consumed $9.73 \pm 3.46$ $\mathrm{mg}$ of nalbuphine in 24 hours as compared to control group where nalbuphine consumption was much higher, $16.46 \pm 3.78 \mathrm{mg}$ with a $p$-value of $>0.001$. Numerical rating scale for pain (NRS) in Control group was very high, more than double of PECS II group, $36.16 \pm$ 5.83 vs $15.89 \pm 5.68$ and it was significant statistically with a $p$-value of $>0.001$. As the patients in PECS II group experienced less pain, so they were more satisfied with their management. Patient satisfaction score was $3.40 \pm 0.72$ in PECS II group as compared to con- 
trol group in which score was $2.27 \pm 0.96$. It was also significant with a $p$-value of $>0.001$, as shown in tableII. PECS II group patients didn't show any block-related complication. Out of 37 patients, 8 (21.62\%) patients in control group experienced nausea and out of them $4(10.81 \%)$ vomited, which was successfully managed with intravenous $4 \mathrm{mg}$ ondansetron.

Table-I: Patient demographic data.

\begin{tabular}{|c|c|c|c|}
\hline Parameters & $\begin{array}{l}\text { PECS II Group } \\
\text { (P) } \mathrm{n}=37\end{array}$ & \multicolumn{2}{|c|}{$\begin{array}{l}\text { Control Group } \\
\text { (C) } n=37\end{array}$} \\
\hline Age (years) & $48(39-62)$ & \multicolumn{2}{|c|}{$49(38-65)$} \\
\hline Weight (kg) & $57 \pm 9.5$ & \multicolumn{2}{|c|}{$58 \pm 7.3$} \\
\hline BMI $\left(\mathrm{kg} / \mathrm{m}^{2}\right)$ & 21.67 & \multicolumn{2}{|c|}{22.55} \\
\hline $\begin{array}{l}\text { Duration of } \\
\text { Surgery (min) }\end{array}$ & $134 \pm 22$ & \multicolumn{2}{|c|}{$128 \pm 29$} \\
\hline \multicolumn{4}{|c|}{$\begin{array}{l}\text { Table-II: Nalbuphine consumption in } 24 \mathrm{hrs}, \mathrm{NRS} \text { and } \\
\text { patient satisfaction score. }\end{array}$} \\
\hline Parameters & $\begin{array}{c}\text { PECS II } \\
\text { Group (P) } \\
\mathbf{n}=37\end{array}$ & $\begin{array}{c}\text { Control } \\
\text { Group (C) } \\
n=37\end{array}$ & $\begin{array}{c}p \text { - } \\
\text { value }\end{array}$ \\
\hline $\begin{array}{l}\text { Nalbuphine } \\
\text { consumption in } 24 \\
\text { hours (Mean } \pm \text { SD) }\end{array}$ & $9.73 \pm 3.46$ & $\begin{array}{l}16.46 \pm \\
3.78\end{array}$ & $<0.001$ \\
\hline $\begin{array}{l}\text { Numerical Rating } \\
\text { Scale for Pain }\end{array}$ & $\begin{array}{c}15.89 \pm \\
5.68\end{array}$ & $\begin{array}{c}36.16 \pm \\
5.83\end{array}$ & $<0.001$ \\
\hline $\begin{array}{l}\text { Patient Satisfaction } \\
\text { Score (Mean } \pm \text { SD) }\end{array}$ & $3.40 \pm 0.72$ & $2.27 \pm 0.96$ & $<0.001$ \\
\hline
\end{tabular}

\section{DISCUSSION}

For the post-operative pain management of breast surgery several regional techniques like thoracic epidural block, infiltration of local anaesthetic, para-vertebral block and intercostal block have been used ${ }^{10}$. Paravertebral block is considered as technique of choicefor breast surgery pain relief but it may not suit MRM because it does not block pectoral nerves (medial and lateral), long thoracic and thoracodorsal nerves. In extensive breast surgeries, specially which involve axillary dissection, paravertebral block fails to provide complete pain relief ${ }^{11,12}$. Moreover, this technique is not without its complications and most of the anaesthetists are not familiar and comfortable performing this block ${ }^{13}$.

A better understanding of nerve supply of breast and surrounding chest wall and increasing use of ultrasound among anaesthetists laid the basis for PECS block first described by Blanco ${ }^{8}$. Initially pectoral block was found to be enough for breast expanders and prosthesis. But for extensive procedures like mastectomy and axillary clearance, pectoral block was not enough so PECS II block was designed. Previously wound infiltration and field block after breast surgery has been used but results were not satisfactory ${ }^{15}$. In pectoral block, local anaesthetic is injected between pectoralis major and minor muscle blocking medial and lateral pectoral nerves therefore it is found to be useful in superficial breast surgeries such as breast augmentation ${ }^{4,13}$. PECS II blocks most of the nerve supply of the breast and is therefore found to be more suitable for breast surgery involving axillary dissection.

Bashandy GMand colleagues compared efficacy of PECS II block in breast surgery patients and also found it better as compared to general anaesthesia alone $^{16}$. They found less Fentanyl consumption, less nausea and vomiting and shorter hospital stay in PECS II group as compared to control group. Wang et al found that PECS II block showed superior results in patients undergoing breast reconstruction with an implant and latissimusdorsi flap ${ }^{17}$. Zhao et al after searching EMBASE and PubMed for randomized controlled trials of PECS II versus general anaesthesia, concluded that in MRM, PECS II block has been found to be an effective block which reduces the opioids used and there is less requirement for postoperative rescue analgesia ${ }^{18}$.

In our study, we didn't record any complication associated with PECS II block. PECS II is a simple and fast acting block and unlike paravertebral and epidural blocks, there is no associated sympathetic block. There are few limitations of our study. First block was performed after giving general anaesthesia which may have altered postoperative pain pattern. Secondly it was not a placebo-controlled double-blind study although the patients and observers were blinded to assigned groups.

\section{Funding Source \\ Departmental resources. \\ CONCLUSION}

This study demonstrates that PECS II block can produce better quality analgesia when combined with general anaesthesia for modified radical mastectomy. It is a simple and highly effective block. We recommend the use of ultrasound for performance of this block as it increases patient safety which is evident from our study as none of our patients develop any block related complications.

\section{CONFLICT OF INTEREST}

This study has no conflict of interest to be declared by any author. 


\section{REFERENCES}

1. Poleshuck EL, Katz J, Andrus CH, Hogan LA, Jung BF, Kulick DI, et al. Risk factors for chronic pain following breast cancer surgery: A prospective study. J Pain 2006; 7(9): 626-34.

2. Kulkarni AR, et al. Factors Associated with Acute Postoperative Pain Following Breast Reconstruction. J Plast Reconstr Aesthet Surg 2017; 11(4): 1-13.

3. Kehlet H, Jensen TS, Woolf CJ. Persistent post- surgical pain: risk factors and prevention. Lancet 2006; 367(6): 1618-25.

4. Grover VK, Mathew PJ, Yaddanapudi S, Sehgal SA. Single dose of preoperative gabapentin for pain reduction and requirement of morphine after total mastectomy and axillary dissection: randomized placebo-controlled double-blind trial. J Postgrad Med 2009; 55(4): 257-60.

5. Kaya M, Oguz G, Senel G, Kadıogulları N. Postoperative analgesia after modified radical mastectomy: the efficacy of interscalene brachial plexus block. J Anesth 2013; 27(6): 862-67.

6. Walder B, Schafer M, Henzi I, Tramer MR. Efficacy and safety of patient-controlled opioid analgesia for acute postoperative pain. A quantitative systematic review. Acta Anaesthesiol Scand 2001; 45(7): 795-804.

7. Andersen KG, Duriaud HM, Jensen HE, Kroman N, Kehlet H. Predictive factors for the development of persistent pain after breast cancer surgery. Pain 2015; 156(12): 2413-22.

8. Blanco R. The 'pecs block': a novel technique for providing analgesia after breast surgery. Anaesth 2011; 66(9): 847-48.

9. Blanco R, Fajardo M, Maldonado TP. Ultrasound description of Pecs II (modified Pecs I): a novel approach to breast surgery. Rev Esp Anestesiol Reanim 2012; 59(9): 470-75.

10. Sidiropoulou T, Buonomo O, Fabbi E, Silvi MB. Prospective comparison of continuous wound infiltration with ropivacaine versus single-injection paravertebral block after modified radical mastectomy. Anesth Analg 2008; 106(3): 997-1001.

11. Wahba SS, Kamal SM. Thoracic paravertebral block versus pectoral nerve block for analgesia after breast surgery. Egypt J Anaesth 2014; 30(2): 129-35.

12. Kulhari S, Bharti N, Bala I, Arora S, Singh G. Efficacy of pectoral nerve block versus thoracic paravertebral block for postoperative analgesia after radical mastectomy: a randomized controlled trial. Br J Anaesth 2016; 117(3): 382-86.

13. Lekhak B, Bartley C, Conacher ID, Nouraei SM. Total spinal anaesthesia in association with insertion of a paravertebral catheter. Br J Anaesth 2001; 86(5): 280-82.

14. Chakraborty A, Khemka R, Datta T, Mitra S. Combipecs, the single-injection technique of pectoral nerve blocks 1 and 2: a case series. J Clin Anesth 2016; 35: 365-68.

15. Talbot H, Hutchinson SP, Edbrooke DL, Wrench I, Kohlhardt SR. Evaluation of a local anesthesia regimen after mastectomy. Anaesthesia 2004; 59(7): 664-67.

16. Bashandy GMN, Abbas DN. Pectoral nerves I and II blocks in multimodal analgesia for breast cancer surgery: a randomized clinical trial. Reg Anesth Pain Med 2015; 40(1): 68-74.

17. Wang K, Zhang X, Zhang T, Yue H, Sun S, Zhao H, et al. The efficacy of ultrasound-guided type II pectoral nerve blocks in peri-operative pain management for immediate reconstruction after modified radical mastectomy: a prospective, randomized study. Clin J Pain 2018; 34(3): 231-36.

18. Zhao J, Han F, Yang Y, Li H, Li Z. Pectoral nerve block in anesthesia for modified radical mastectomy. A meta-analysis based on randomized controlled trials. Medicine (Baltimore) 2019; 98(18): e15423. 